\title{
Microbial mediation of stromatolite formation in karst-water creeks
}

\author{
Andrew Bissett, ${ }^{1}$ Dirk de Beer, and Raphaela Schoon \\ Max Planck Institute for Marine Microbiology, Celsiusstraße 1, 28359 Bremen, Germany
}

\author{
Fumito Shiraishi, Andreas Reimer, and Gernot Arp \\ Geoscience Centre, University of Göttingen, Goldschmidtstraße 3, D-37077 Göttingen, Germany
}

\begin{abstract}
Epilithic and endolithic biofilms were found to control the formation of stromatolites in karst-water creeks. We used microsensors to determine the influence of biological processes on chemical conditions within the microenvironment of crystal nucleation sites: the stromatolite surface. Phototrophic members of the biofilms consisted of mainly cyanobacteria and diatoms. Oxygen, $\mathrm{pH}$, calcium, and carbonate concentration microprofiles at the stromatolite surface and boundary layer showed a strong diurnal rhythm of calcium carbonate precipitation. During illumination, photosynthesis caused oxygen production, a marked increase in $\mathrm{pH}$ and $\mathrm{CO}_{3}^{2-}$ concentrations, and a decrease in $\mathrm{Ca}^{2+}$ concentration at the stromatolite surface due to calcium carbonate precipitation. The opposite occurred in the dark, indicating decalcification. Calcite was approximately 16 times oversaturated in the bulk water, photosynthesis induced an increase of the supersaturation to $>27$ at the stromatolite surface under illumination, and respiration induced a decrease of the supersaturation to $<10$ in the dark. Photosynthetically stimulated calcium carbonate precipitation was confirmed by radioactive isotope $\left({ }^{45} \mathrm{Ca}^{2+}\right)$ uptake studies. Over a $24 \mathrm{~h}$ light : dark cycle, biofilms showed net calcification. Biotic activity within the stromatolite has a large effect on conditions at its surface and, therefore, contributes considerably to the stromatolite precipitation process.
\end{abstract}

Calcareous stromatolites are amongst the oldest known biological formations, and they provide insight into early Earth environments and climates. For this reason, it is essential to understand the processes governing their formation and dissolution. Presently forming stromatolites are rare in marine settings, but they are a common and much investigated feature of karst regions (Grüninger 1965; Merz-Preiss and Riding 1999). Such karst-water creek stromatolites have been termed tufa stromatolites, and they are defined as macroscopically laminated benthic microbial deposits produced by precipitation of minerals on organic tissue (Riding 1990). The role of biofilms in the formation of these stromatolites is still under debate. Early studies suggested that precipitation was primarily caused by $\mathrm{CO}_{2}$ assimilation by cyanobacteria, eukaryotic algae, and plants (Pia 1926, 1933; Wallner 1934). Later hydrochemical investigations, however, concluded that precipitation is largely physicochemically driven by rapid $\mathrm{CO}_{2}$ degassing from high- $p \mathrm{CO}_{2}$ groundwater (Usdowski et al. 1979; Herman and Lorah 1987; Merz-Preiss and Riding 1999), with only a minor contribution from photosynthetic $\mathrm{CO}_{2}$ removal. This conclusion was reached when it was observed

\footnotetext{
${ }^{1}$ Corresponding author (abissett@mpi-bremen.de; phone: +49 421-2028830; fax: +49 421-2028690).

Acknowledgments

We thank the microsensor technicians at the Max Planck Institute for Marine Microbiology, Bremen, for assistance with microsensor construction, and Lubos Polerecky for the microprofiling software. We thank Hakhyun Nam (Kwangwoon University, Korea) for supplying the carbonate ionophore. This project is part of the Research Unit "Geobiology of Organo- and Biofilms" funded by the German Research Foundation (DFGFOR 571, publication 23).
}

that calcium and dissolved inorganic carbon (DIC) were lost from water as it moved downstream, but no diurnal pattern was observed in creek-water chemistry. Even in instances where phototrophic communities were observed to affect whole-stream inorganic carbon dynamics (Spiro and Pentecost 1991), the development of tufa travertine deposits was seen as a largely abiotic process. The biofilms in the creeks investigated in the current study were very thin $(<100 \mu \mathrm{m})$, and indeed whole-stream-water chemistry parameters were hardly affected by biological activity. We tested the hypothesis that in these thin biofilms, strong shifts in local water chemistry are possible due to photosynthetic and respiratory activity, and that these shifts have highly localized effects on the stromatolite surface, where calcium carbonate precipitates.

Precipitation of calcite is initiated when calcium carbonate becomes supersaturated and suitable nucleation sites are present. Karst waters have a low $\mathrm{Mg}^{2+}: \mathrm{Ca}^{2+}$ ratio $(<2)$, and, therefore, low-Mg-calcite is usually the main component in their stromatolite formations (Irion and Müller 1968; Arp et al. 2001). Photosynthesis and respiration can have a large effect on carbonate chemistry. Photosynthesis removes $\mathrm{CO}_{2}$ and shifts the carbonate equilibrium toward carbonate, thereby increasing calcite saturation state $(\Omega)$. Respiration increases $\mathrm{CO}_{2}$ and therefore has the opposite effect. Consequently, photosynthesis can lead to calcification, while respiration can lead to calcite dissolution when $\Omega$ decreases to values below one. In other aquatic settings, such as hypersaline lakes (Ludwig et al. 2005) and marine sediments (Werner et al. 2008) microsensor studies have demonstrated the potential for phototrophic communities to remove large amounts of $\mathrm{CO}_{2}$ and enhance calcification. For stromatolite-forming biofilms in freshwater settings, this has not yet been investigated, and the view still prevails 
that the primary mechanism behind stromatolite precipitation is $\mathrm{CO}_{2}$ degassing (Pentecost 1995).

It is also thought that, in addition to metabolic activity, biofilm components, particularly acid-organic compounds, in extracellular polymeric substances (EPS) that can strongly bind $\mathrm{Ca}^{2+}$ influence $\mathrm{CaCO}_{3}$ precipitation. EPS is a common component of biofilms (Decho 1990; Nealson 1997; Neu and Lawrence 1999) and may contribute to precipitation in two ways: (1) suitably arranged acidic EPS groups create a template for precipitation and promote nucleation upon saturation with $\mathrm{Ca}^{2+}$ (organomineralization), and (2) the decomposition of EPS liberates $\mathrm{HCO}_{3}^{-}$ and $\mathrm{Ca}^{2+}$ and thereby increases calcite oversaturation (Arp et al. 2003; Trichet and Defarge 1995; Decho et al. 2005; Dupraz and Visscher 2005).

Previous studies in the Deinschwanger creek (see Methods) (Arp et al. 2001) were inconclusive as to the exact role of the biofilm in stromatolite formation, and diurnal rhythms had not been observed in this creek (Arp et al. 2003) due to resolution limitations of the bulk-water analysis methods used. Previous results have not excluded the possibility that the phototrophic biofilms diurnally control the local, i.e., on the stromatolite surface, water chemistry. We therefore performed both in situ and ex situ experiments to investigate the role of the biofilm in stromatolite formation in more detail. We used fine-scale microsensor and $\beta$-imaging techniques to elucidate the influence of biofilm activity on carbonate chemistry and precipitation at the stromatolite surface.

\section{Materials and methods}

Creek sites-The Deinschwanger creek is located near Nürenberg, in southern Germany $\left(49^{\circ} 23^{\prime} \mathrm{N}, 11^{\circ} 28^{\prime} \mathrm{E}\right)$, and the Westerhöfer creek is located near the Harz Mountains in northern Germany $\left(51^{\circ} 45^{\prime} \mathrm{N}, 10^{\circ} 5^{\prime} \mathrm{E}\right)$. Both sites have been used for previous studies on calcification and are described in more detail in Arp et al. (2001) and Usdowski et al. (1979). Both sites show active laminated stromatolite formation of up to $1.8 \mathrm{~mm} \mathrm{yr}^{-1}$.

Sampling-Water samples for DIC and calcium measurements were taken from both the creeks and the aquariums during incubation. Fifteen-milliliter samples were filtered $(0.2 \mu \mathrm{m})$ into exetainers (Labco Ltd.) containing $\mathrm{HgCl}_{2}$, sealed without air bubbles, and stored in the dark at $4^{\circ} \mathrm{C}$ until analysis.

Stromatolite samples for laboratory incubations were taken with a motorized core-drilling device in October 2005 and 2006 from Deinschwanger creek and May 2006 from Westerhöfer creek. Samples were stored in ambient creek water in coolers and transported to the laboratory within $24 \mathrm{~h}$. At Deinschwanger creek, samples were collected from two distinct sites. Site 1 was a small stromatolite cascade downstream of the spring in a shaded site in the forest. The stromatolite was laminated, and it was several centimeters thick. At this site, the creek was $\sim 1-5 \mathrm{~cm}$ deep and exhibited a fast flow rate of $\sim 0.7 \mathrm{~m} \mathrm{~s}^{-1}$. Site 2 was a wellilluminated, $\sim 20$-cm-deep section of the lower creek, and it had a lower flow rate $\left(\sim 0.05 \mathrm{~m} \mathrm{~s}^{-1}\right)$ than site 1 . Site 2 exhibited thin (up to $1 \mathrm{~mm}$ ), fragile carbonate crusts. At the Westerhöfer creek, samples were taken from only one site, which was similar to site 1 at the Deinschwanger creek. Here, the creek was fast flowing and shallow, with laminated stromatolite several centimeters thick. Ambient $\mathrm{pH}$ at all sampling sites was 8.4.

In the laboratory, samples were stored in temperaturecontrolled $\left(10^{\circ} \mathrm{C}\right)$, aerated recirculating aquariums (total volume $\sim 30$ liters) containing creek water. Creek water was collected without air bubbles, in 20-liter plastic containers, at the same time cores were taken. The water was stored in the dark at $4{ }^{\circ} \mathrm{C}$ until it was added to the aquarium reservoir. Samples were illuminated at $150 \mathrm{~mol}$ quanta $\mathrm{m}^{-2} \mathrm{~s}^{-1}$ on a $12 \mathrm{~h}$ light : dark (LD) cycle.

Water analyses-Bulk water $\mathrm{pH}$ was determined with a MA130 pH electrode (Mettler Toledo) directly in the creek and in the experimental aquaria. $\mathrm{Ca}^{2+}$ was determined by inductively coupled plasma-optical emission spectrometry (ICP-OES; Perkin Elmer Optima 3300 DV), and DIC was determined by $\mathrm{CO}_{2}$ coulometer (UIC Coulometrics).

Algal pigment analysis - Triplicate biofilm samples from Deinschwanger creek (sites 1 and 2) and single samples from incubation experiments were analyzed for algal pigments to assess the change in algal communities induced by experimental conditions. Samples taken freshly from the creek were stored on ice and frozen $\left(-20^{\circ} \mathrm{C}\right)$ as soon as possible $(<24 \mathrm{~h})$. Samples used for laboratory studies were immediately frozen after the incubations. For analysis, frozen samples were placed in $15-\mathrm{mL}$ centrifuge tubes, in $3 \mathrm{~mL}$ of $100 \%$ acetone, and sonicated on ice for $10 \times$ $1 \mathrm{~min}$. Pigments were extracted from the mixture at $-20^{\circ} \mathrm{C}$ overnight. Samples were then filtered (Acrodisc CR syringe filter, $0.45-\mu \mathrm{m}$ pore size, PALL GmbH, Dreieich, Germany, Gellman Laboratory) and diluted with water to a final concentration of $70 \%$ acetone. Photopigments were separated on a high performance liquid chromatography (HPLC) (2690 separation module, Waters), equipped with a Eurospher-100 C18, 5- $\mu \mathrm{m}$ Vertex column (Knauer), according to the method of Wright et al. (1991). Absorption spectra of the separated compounds were measured on a Waters 996 photo-diode-array detector, and pigments were quantified and identified by comparison to pigment standards (DHI Waters and Environment).

Microelectrode measurements and calculations-Microelectrodes are ideal tools to measure chemical gradients in biotic systems at fine $(\mu \mathrm{m})$ scales (see Gieseke and de Beer [2004] for a review of microsensor form, function, and application to microbiological samples). Microelectrode profiles of $\mathrm{pH}, \mathrm{O}_{2}$, and $\mathrm{Ca}^{2+}$ concentration gradients were measured in situ at the two creeks. Profiles of these and $\mathrm{CO}_{3}^{2-}$ were also made ex situ, in the laboratory, using biofilm-covered stromatolite cores.

Liquid-membrane $\mathrm{Ca}^{2+}$ and $\mathrm{pH}$ sensors $($ tip $=20 \mu \mathrm{m})$ were prepared and calibrated as described previously (de Beer et al. 1997, 2000). Liquid-membrane $\mathrm{CO}_{3}^{2-}$ sensors were constructed similarly to the other liquid-membrane sensors and calibrated as described in de Beer et al. 
(unpubl.). For carbonate system components, pK1 (6.464) and pK2 (10.489) were calculated after Millero (1979), for freshwater and at $10^{\circ} \mathrm{C}$. Fast-responding $\mathrm{O}_{2}$ microsensors (tip $=10 \mu \mathrm{m})$ were prepared as described previously (Revsbech 1989). Biofilms were very thin $(50-100 \mu \mathrm{m})$, and it was difficult distinguish the biofilm surface from that of the calcium carbonate tufa. Indeed the biofilms were partly endolithic. The glass electrodes could not penetrate the hard mineral surface. All electrodes were, therefore, placed at the stromatolite-biofilm surface while the sample was viewed through a dissection microscope. The surface was then set at 0 , and all measurements were made above the surface. Negative distances indicate that the sensor was above the stromatolite-water interface, that is, in the overlying water. Sensors were connected to a micromanipulator that was fixed onto a motorized stage (VT-150, Micos), which allowed reproducible positioning of the sensor tip with $1 \mu \mathrm{m}$ precision. The microelectrodes were connected to a picoammeter $\left(\mathrm{O}_{2}\right.$ electrode $)$ or a millivoltmeter, and the meter output was collected by a dataacquisition device (NI-Daq 6015, National Instruments). After positioning at the surface, profiling was done automatically; motor control and data acquisition were performed with a computer and custom-written software $(\mu$-Profiler, Dr. L. Polerecky). All profiles were corrected for offset to ion levels in the bulk liquid, as measured by the water analyses. For in situ microelectrode measurements, the micromanipulator was mounted to a heavy stand and placed in the creek, on the downstream side of the measuring position.

Interfacial fluxes $(J)$ were calculated from the concentration profiles using Fick's first law:

$$
J=D \times(d c / d x)
$$

where $D$ is the diffusion coefficient, and $d c / d x$ is the interfacial concentration gradient, i.e., the concentration gradient in the mass boundary layer directly adjacent to the stromatolite surface. The diffusion coefficients of $\mathrm{O}_{2}$ and $\mathrm{Ca}^{2+}$ are literature-derived values corrected for temperature and type of counterion (Broeker and Peng 1974; Li and Gregory 1974). Estimated diffusion coefficients of oxygen are, $4^{\circ} \mathrm{C}: 1.28 \times 10^{-9} \mathrm{~m}^{2} \mathrm{~s}^{-1} ; 10^{\circ} \mathrm{C}: 1.57 \times 10^{-9} \mathrm{~m}^{2} \mathrm{~s}^{-1}$; and $17^{\circ} \mathrm{C}: 1.934 \times 10^{-9} \mathrm{~m}^{2} \mathrm{~s}^{-1}$. Diffusion coefficients for $\mathrm{Ca}^{2+}$ with $\mathrm{HCO}_{3}^{2-}$ as counterion are, $4^{\circ} \mathrm{C}: 0.546 \times 10^{-9} \mathrm{~m}^{2}$ $\mathrm{s}^{-1} ; 10^{\circ} \mathrm{C}: 0.67 \times 10^{-9} \mathrm{~m}^{2} \mathrm{~s}^{-1}$; and $17^{\circ} \mathrm{C}: 0.827 \times 10^{-9} \mathrm{~m}^{2}$ $\mathrm{s}^{-1}$.

Calcite saturation is given by the saturation-state omega,

$$
\Omega=\left[\mathrm{Ca}^{2+}\right] \times\left[\mathrm{CO}_{3}^{2-}\right] / K_{(\text {calcite) }}
$$

where the numerator is the ion concentration product (ion activities were not incorporated), and the denominator the solubility product. $\Omega>1$ indicates supersaturation, while $\Omega$ $<1$ indicates undersaturation. The solubility product for calcite was taken from Plummer and Busenberg (1982).

Incubation with radiotracers - Stromatolite samples from both creeks were subject to radiotracer incubation with ${ }^{45} \mathrm{Ca}^{2+}$. Stromatolite samples were incubated under three experimental conditions: (1) under illumination at $150 \mathrm{~mol}$ quanta $\mathrm{m}^{-2} \mathrm{~s}^{-1}$, (2) in the dark, and (3) fixed with formaldehyde $(2 \%)$ control. Samples were analyzed by both scintillation counting and $\beta$-imaging. During each treatment, stromatolite samples were incubated in $400 \mathrm{~mL}$ of filtered creek water at $20^{\circ} \mathrm{C}$ and gently stirred. Prior to addition of the radiotracer, the stromatolite pieces were left for at least $2 \mathrm{~h}$ to recover from the transfer. The radioactive tracer, ${ }^{45} \mathrm{Ca}^{2+}$ as $\mathrm{CaCl}_{2}$ (Amersham Pharmacia Biotech), was added to each beaker to a final activity of $3 \mathrm{kBq} \mathrm{mL}-1$

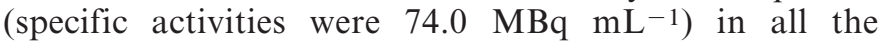
experiments. Samples were incubated with tracer for 1, 3, 6 , and $24 \mathrm{~h}$.

After the incubation, the samples were fixed in $2 \%$ formaldehyde for $2 \mathrm{~h}$. The fixed stromatolite samples were then washed four times for $5 \mathrm{~min}$ in $200 \mathrm{~mL}$ of filtered creek water. Samples were then left to air dry overnight.

Samples for scintillation counting were weighed and dissolved in $10 \mathrm{~mL}$ of $12 \mathrm{~N} \mathrm{HCl}$. Two milliliters of dissolved sample were then added to $3 \mathrm{~mL}$ of Ultima gold scintillation cocktail (Perkin-Elmer), and radioactivity was determined using a Packard TR 2500 liquid scintillation counter operating in efficiency-tracing mode to correct for quench.

Samples for $\beta$-imaging were immersed in Epothin resin (Buehler), cut into $\sim 4-\mathrm{mm}$ cross sections with a diamond band saw (Proxon MBS 240E), and polished flat with a Buehler Beta polishing system. $\beta$-imaging autoradiographs of the stromatolite samples were acquired in a MicroImager (Laniece et al. 1998). The resin fixation and polishing process occasionally produced artifacts in the data obtained by the $\beta$-imager. These artifacts were caused by air bubbles in the resin, which filled with radioactive dust when the samples were cut and polished. They were easily recognizable as a circular "hotspot" that coincided with an airbubble-induced hole. These artifacts were removed from the analysis with Photoshop CS (Adobe Systems Inc.).

\section{Results}

Sample description and pigment analysis-Stromatolite biofilms in both the Deinschwanger and Westerhöfer creeks were green-brown and composed of cyanobacteria, diatoms, and associated nonphototrophic bacteria. Pigment composition was analyzed only for samples from Deinschwanger creek, site 1 (small tributary on northern valley side) and site 2 (lower end section, near end of stromatolite deposition).

Samples from site 1 consisted of thick stromatolite cores, the tops of which were covered by an $\sim 50-100-\mu \mathrm{m}$-thick green and brown biofilm, while those at site 2 consisted of an equally thick, brown-colored biofilm covering a 1-mm-thick, fragile carbonate crust. The appearance of the samples did not change markedly during the study, but biofilm thickness sometimes increased slightly. Pigment composition did not change markedly during incubation (Fig. 1). The pigment concentrations and compositions in samples at the end of incubations were similar to those from the creek, showing that the algal community remained stable during incubations. Pigment concentrations were higher at site 2. The compositions of the pigments were similar at both sites. Pigments were dominated by chlorophyll $\alpha$ and $\beta$-carotene. Smaller amounts of fucoxanthene, zeaxanthine, phaeophy- 


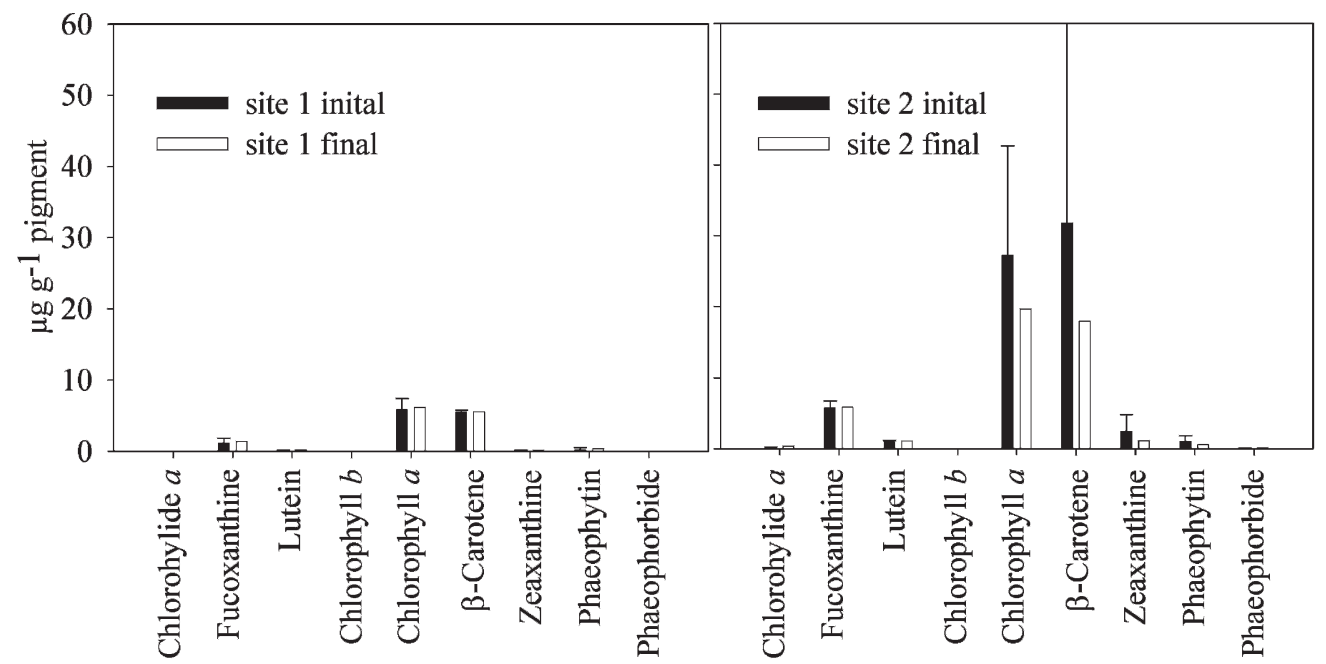

Fig. 1. Algal pigments in tufa samples from Deinschwanger creek (sites 1 and 2) prior to and following incubation (initial samples $n=3$; final samples $n=1$ ).

tin, and chlorohylide $\alpha$ were also seen in both sites. Fucoxanthene, zeaxanthine, and phaeophytin indicate the presence of cyanobacteria and diatoms in these biofilms.

In situ measurements - In situ profiling was complicated by the heterogeneous substrate topography, debris flowing down the river, and difficult visualization of the hard substratum under poor light conditions. Consequently, in situ microprofiling was often interrupted by breakage of microsensors. In situ concentration-gradient profiling was successfully carried out for $\mathrm{O}_{2}, \mathrm{pH}$, and $\mathrm{Ca}^{2+}$ in both Deinschwanger and Westerhöfer creeks, although not all

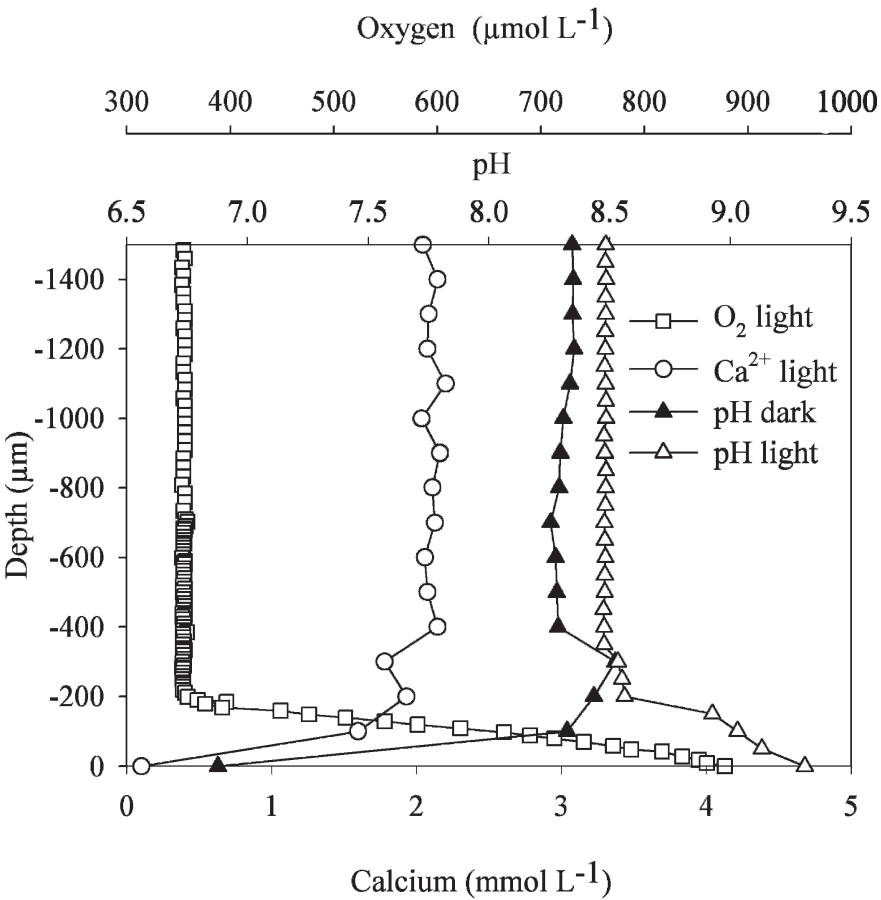

Fig. 2. In situ concentration profiles of $\mathrm{Ca}^{2+}, \mathrm{pH}$, and $\mathrm{O}_{2}$ at Deinschwanger creek. species could be profiled both in the day and night at both sites (Figs. 2, 3). The data clearly indicate a day to night change in chemical conditions on the stromatolite surface. Fluxes calculated from profiles are given in Table 1. Photosynthesis occurred at the stromatolite surface of both creeks in daylight and caused a flux of $\mathrm{O}_{2}$ from the biofilm to the water column, an increase in $\mathrm{pH}$ at the stromatolite surface, and a concomitant decrease in $\mathrm{Ca}^{2+}$ ion concentration. The night profiles showed the opposite. In Westerhöfer creek, a decrease in $\mathrm{O}_{2}$ concentration occurred with respiration, and an increase in $\mathrm{Ca}^{2+}$ concentration was evident. At Deinschwanger creek, the only $\mathrm{pH}$ profile was obtained at night, and it showed a decrease in $\mathrm{pH}$ at the stromatolite surface, indicating respiratory activity. The efflux of $\mathrm{Ca}^{2+}$ in the dark was lower than its influx in the light; thus, during a $12: 12 \mathrm{~h}$ photoperiod, there was a net

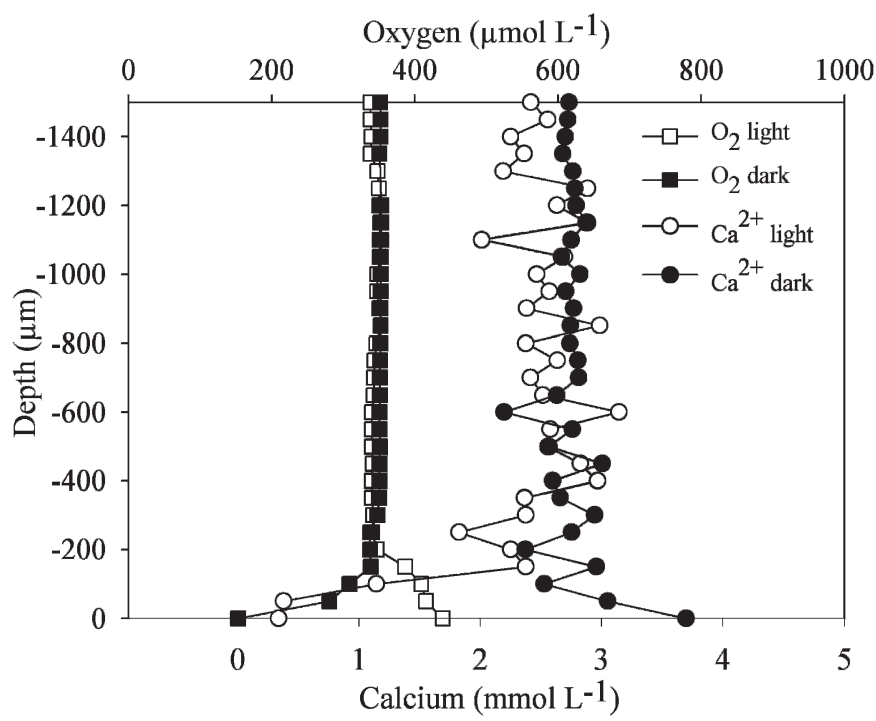

Fig. 3. In situ concentration profiles of $\mathrm{Ca}^{2+}$ and $\mathrm{O}_{2}$ at Westerhöfer creek. 
Table 1. In situ fluxes $\left(\mathrm{mol} \mathrm{m} \mathrm{m}^{2} \mathrm{~s}^{-1}\right)$ of oxygen and calcium in Deinschwanger and Westerhöfer creeks. A negative flux indicates a flux from the water column toward the tufa surface.

\begin{tabular}{lccrrr}
\hline \hline & \multicolumn{2}{c}{ Deinschwanger creek } & & \multicolumn{2}{c}{ Westerhöfer creek } \\
\cline { 2 - 3 } \cline { 5 - 6 } & Oxygen & Calcium & & Oxygen & Calcium \\
\hline Day & $5.6 \times 10^{-6}$ & $-2.0 \times 10^{-5}$ & & $1.0 \times 10^{-6}$ & $-1.3 \times 10^{-5}$ \\
Night & & & $-9.1 \times 10^{-7}$ & $7.3 \times 10^{-6}$ & \\
\hline
\end{tabular}

flux of $1.2 \times 10^{-5} \mathrm{~mol} \mathrm{Ca}^{2+} \mathrm{m}^{2} \mathrm{~s}^{-1}$ toward the stromatolite surface over a full $24-\mathrm{h}$ cycle.

Ex situ measurements-The in situ measurements were complemented with a detailed ex situ study. In samples from both creeks, under illumination, $\mathrm{O}_{2}$ and $\mathrm{pH}$ increased due to photosynthesis, coincident with a decrease in $\mathrm{Ca}^{2+}$. The opposite occurred under dark conditions (Figs. 4, 5). Respiration resulted in $\mathrm{O}_{2}$ consumption and a decrease in $\mathrm{pH}$. The $\mathrm{Ca}^{2+}$ profile also changed with this change in metabolism, such that $\mathrm{Ca}^{2+}$ uptake $\left(\mathrm{CaCO}_{3}\right.$ precipitation) ceased, and its release from the tufa (apparent $\mathrm{CaCO}_{3}$ dissolution) occurred. The carbonate concentration increased at the stromatolite surface during light conditions, and carbonate concentration decreased in the dark (Fig. 5). Fluxes calculated from the profiles are shown in Table 2. The fluxes of both $\mathrm{O}_{2}$ and $\mathrm{Ca}^{2+}$ were similar during in situ measurements and the laboratory incubations. Accurate quantitative comparisons were difficult because of the heterogeneity of the samples.

Carbonate profiles, measured by carbonate microsensors in several samples from Westerhöfer creek, agreed well with carbonate profiles modeled from the bulk-water DIC concentrations and $\mathrm{pH}$ microprofiles using the $\mathrm{CO}_{2}$ system equations (Zeebe and Wolf-Gladrow 2001) (data not shown). Subsequently, bulk-water DIC and $\mathrm{pH}$ microprofiles were used to predict the $\mathrm{CO}_{3}^{2-}$ concentration and $\Omega$ profiles for tufa samples (Fig. 6). These calculations revealed an increase in $\mathrm{CO}_{3}^{2-}$ in light, which caused $\Omega$ to become $>20$. The opposite occurred in the dark, when $\mathrm{CO}_{3}^{2-}$ and $\Omega$ became $<10$.

Water flow had a small effect on the photosynthesis rates. Increasing the flow rate from $0.009 \mathrm{~L} \mathrm{~s}^{-1}$ to $0.035 \mathrm{~L}$ $\mathrm{s}^{-1}$ caused the diffusive boundary layer (DBL) to decrease in thickness from $\sim 600 \mu \mathrm{m}$ to $200 \mu \mathrm{m}$ and the areal rate of $\mathrm{O}_{2}$ production to increase from $1.93 \times 10^{-6}$ to $2.47 \times$ $10^{-6} \mathrm{~mol} \mathrm{~m} \mathrm{~m}^{-2} \mathrm{~s}^{-1}$. The height of the DBL indicates the range over which diffusion determines chemical gradients. The smaller the DBL, the faster chemicals can move between the overlying water and the sediment surface. Flow rates in situ were very fast, and the DBL was probably slightly less than that in our ex situ experiments. This, however, does not change the interpretation of the clear diurnal calcium dynamics observed.

Radiotracer incubations - Scintillation counts of whole samples showed that calcium was incorporated under all conditions, but rates of incorporation in the light were approximately twice as high as in the dark and controls (Fig. 7). Dark rates equaled control rates, indicating that in the dark, the calcium uptake was mainly isotopic exchange. The $\beta$-imaging (Fig. 8) confirmed that uptake of ${ }^{45} \mathrm{Ca}^{2+}$ was stimulated by light, and that $\mathrm{Ca}$ uptake preferentially occurred at the stromatolite surface. Indeed, ${ }^{45} \mathrm{Ca}^{2+}$ uptake appears to have occurred most strongly in the middle of the biofilm, but it could be seen throughout the whole biofilm (photosynthetic zone), not only at the biofilm-

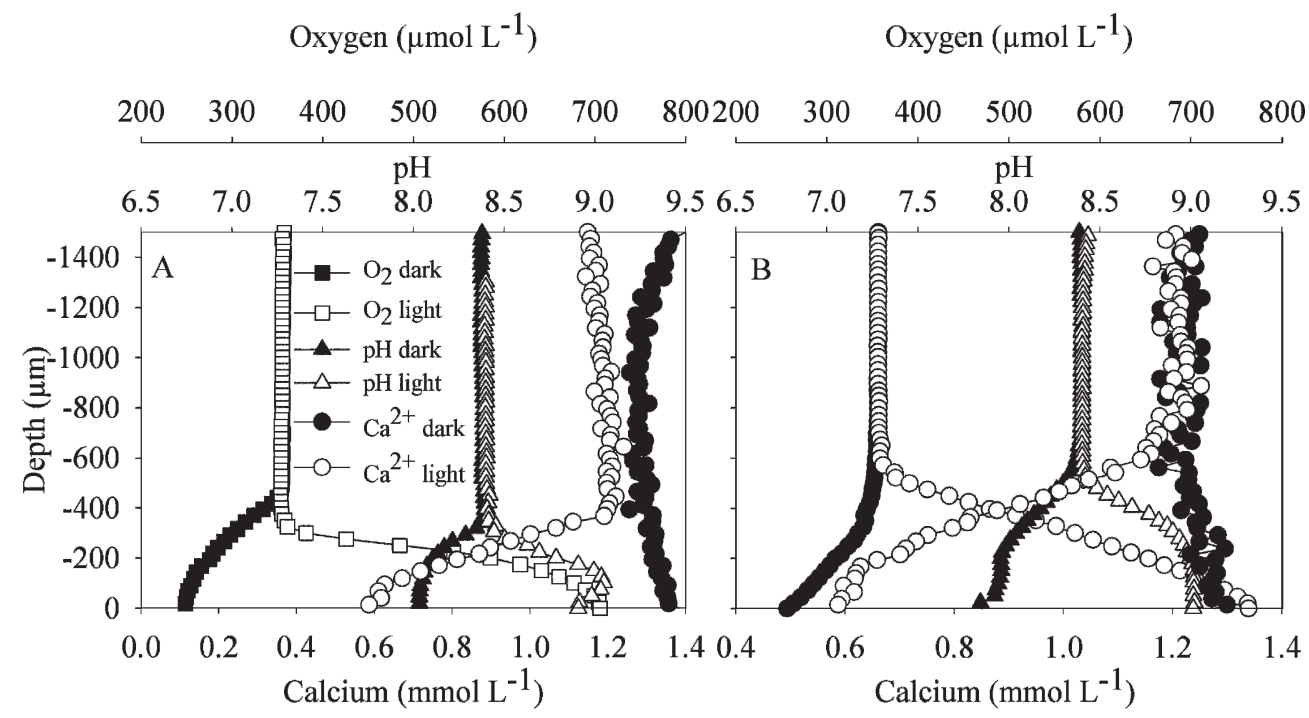

Fig. 4. Ex situ concentration profiles of $\mathrm{Ca}^{2+}, \mathrm{pH}$, and $\mathrm{O}_{2}$ from Deinschwanger creek tufa biofilm samples: (A) site 1, (B) site 2 . 


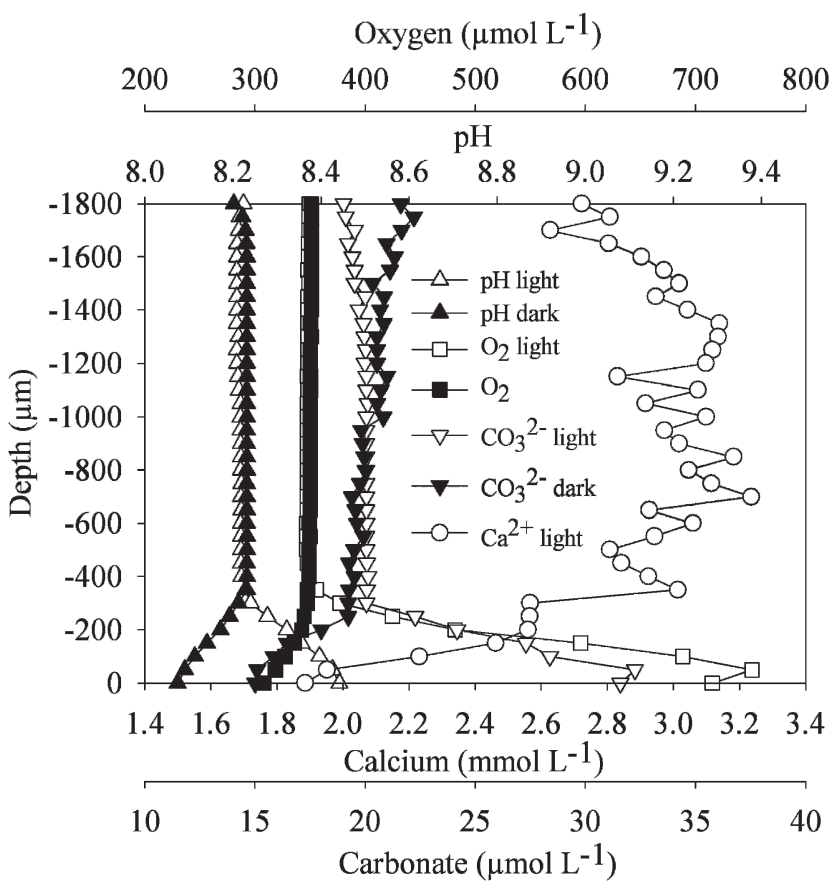

Fig. 5. Ex situ concentration profiles of $\mathrm{Ca}^{2+}, \mathrm{pH}, \mathrm{O}_{2}$, and $\mathrm{CO}_{3}^{2-}$ from Westerhöfer creek tufa biofilm samples.

overlying water interface. In the dark and control samples, radioactive signals were detected throughout the whole sample.

\section{Discussion}

There has been a long controversy regarding whether stromatolites in karst-water creeks are formed by biological removal of $\mathrm{CO}_{2}$, so by photosynthesis, or by $\mathrm{CO}_{2}$ degassing. It is, however, conceivable that both processes occur simultaneously in the creek: in the water column, the carbonate system is driven by abiotic forces, as suggested previously, while stromatolite formation is driven by metabolic processes. We propose that the most dominant calcification process in the creek does not result in stromatolite formation, but it occurs in the water column, and the precipitated calcium carbonate is washed from the spring area as suspended crystals. This calcification process is driven by $\mathrm{CO}_{2}$ degassing and manifests itself as a downstream calcium loss from the water column, and a downstream $\mathrm{pH}$ increase, with no diurnal pattern to the calcium loss, stream $\mathrm{pH}$, or saturation-state parameters.
This physical process has been well documented in similar systems, and it was also found in the creeks of this study (Usdowski et al. 1979; Merz-Preiss and Riding 1999).

Parallel to this physicochemical process, biologically controlled calcification results in stromatolite formation. Local $\mathrm{CO}_{2}$ fixation by photosynthesis leads to calcification in the top $100 \mu \mathrm{m}$ of the stromatolite surface. Interestingly, apparent decalcification is observed during the night, due to respiration; so, locally, the biological processes can counter the massive physical process of outgassing. The biological processes exert no significant influence over the whole stream carbonate system, and so they do not induce diurnal rhythms in $\mathrm{pH}$ and $\mathrm{Ca}^{2+}$ concentrations in the water column. Indeed, a rough, conservative calculation can be made regarding the relative contributions of the two processes. Assuming about $100 \mathrm{~m}^{2}$ of stromatolite area, a flow rate of $2 \mathrm{~L} \mathrm{~s}^{-1}, \mathrm{Ca}^{2+}$ flux estimated from actual tufa deposits ( 4-mm-thick annual lamination, unpubl. data), and $\mathrm{Ca}^{2+}$ loss from the bulk water of $0.4 \mathrm{mmol} \mathrm{L}^{-1}$, stromatolite precipitation accounts for less than $15 \%$ of the creek's Ca loss. The biological processes are only measurable at the stromatolite surface with high-resolution methods, such as microsensors. The biological effects on the water-column $\mathrm{pH}$ or $\mathrm{Ca}^{2+}$ concentrations are lost in the overwhelming background of the larger $\mathrm{CO}_{2}$ degassingdriven process. However, locally, the effects of biological processes are highly significant. The biological precipitation process, which results in stromatolite growth, manifests itself as precipitation at the stromatolite surface and exhibits a clear diurnal rhythm, synchronous with biofilm photosynthetic and respiration processes. The present microsensor $\mathrm{pH}, \mathrm{O}_{2}$, and $\mathrm{Ca}^{2+}$ profiles clearly demonstrate this diurnal pattern and, therefore, a decisive biological control on the microenvironment and $\mathrm{Ca}^{2+}$ removal for stromatolite formation.

It has also been argued that biofilms merely act as nucleation site for calcification or concentrate calcium by binding to EPS (Dupraz and Visscher 2005). With this in mind, two possible scenarios will be discussed in view of the observed $\mathrm{Ca}^{2+}$ microprofiles and radiotracer data: (1) $\mathrm{Ca}^{2+}$ uptake in newly produced EPS without precipitation and later $\mathrm{Ca}^{2+}$ release due to $\mathrm{pH}$ decrease or EPS decomposition causes precipitation in a second step, or (2) $\mathrm{CaCO}_{3}$ precipitation is caused by photosynthetic $\mathrm{CO}_{2}$ removal.

The first scenario does not explain our radiotracer data: EPS is produced mainly under illumination and decomposes in the dark (Decho and Lopez 1993; Epstein 1997; Staats et al. 2000). If release of $\mathrm{Ca}^{2+}$ from EPS were driving supersaturation under these conditions, $\mathrm{CaCO}_{3}$ would be

Table 2. Ex situ fluxes (mol m $\mathrm{m}^{2} \mathrm{~s}^{-1}$ ) of oxygen, calcium, and carbonate in Deinschwanger and Westerhöfer creeks. Numbers in parentheses identify site 1 or 2 . A negative flux indicates a flux toward the tufa surface.

\begin{tabular}{|c|c|c|c|c|c|}
\hline & \multicolumn{2}{|c|}{ Deinschwanger creek } & \multicolumn{3}{|c|}{ Westerhöfer creek } \\
\hline & Oxygen & Calcium & Oxygen & Calcium & Carbonate \\
\hline Light & $\begin{array}{l}4.37 \times 10^{-6}(1) \\
1.62 \times 10^{-6}(2)\end{array}$ & $\begin{array}{l}-1.30 \times 10^{-6}(1) \\
-8.88 \times 10^{-7}(2)\end{array}$ & $3.24 \times 10^{-6}$ & $-3.42 \times 10^{-6}$ & $2.39 \times 10^{-7}$ \\
\hline Dark & $\begin{array}{r}-3.75 \times 10^{-7}(1) \\
-4.3 \times 10^{-7}(2)\end{array}$ & $\begin{array}{c}1.16 \times 10^{-7}(1) \\
0(2)\end{array}$ & $-2.47 \times 10^{-7}$ & & $-1.44 \times 10^{-7}$ \\
\hline
\end{tabular}



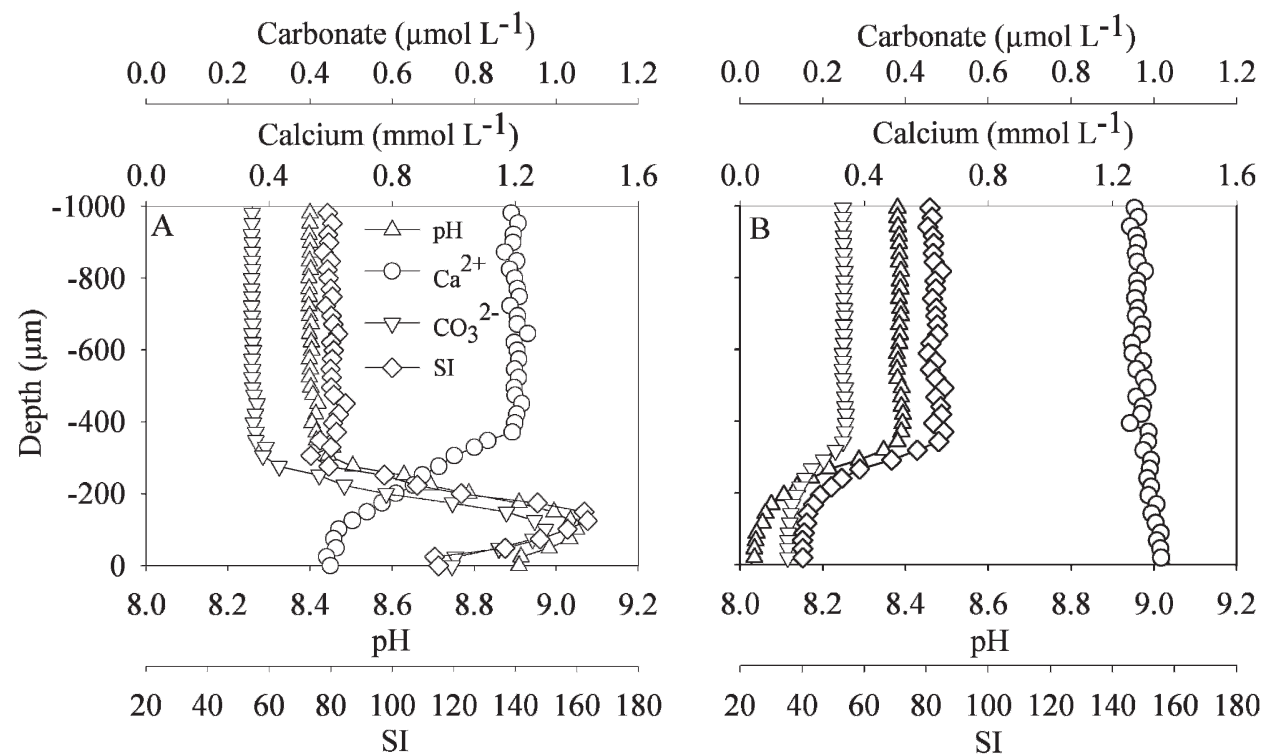

Fig. 6. Measured microprofiles of $\mathrm{pH}$ and $\mathrm{Ca}^{2+}$ in the (A) light and (B) dark and predicted $\mathrm{CO}_{3}^{2-}$ and calcite saturation $\Omega$ calculated from the measured $\mathrm{pH}$ profiles and bulk-water DIC concentrations. Samples are from Deinschwanger creek, site 1.

precipitated in the dark. All samples were illuminated immediately before the tracer experiment. If release of $\mathrm{Ca}^{2+}$ bound to EPS were initiating precipitation, ${ }^{45} \mathrm{Ca}^{2+}$ uptake should have been seen in both the light and dark treatments - in the light, as the tracer was bound to EPS, and in the dark, as previously bound $\mathrm{Ca}^{2+}$ was released, leading to $\mathrm{CaCO}_{3}$ supersaturation and precipitation. This was not the case; ${ }^{45} \mathrm{Ca}^{2+}$ uptake was observed only in the light. We do not exclude that $\mathrm{pH}$ changes induced by photosynthesis-respiration cycles make EPS more amenable to $\mathrm{Ca}^{2+}$ binding in the light and release in the dark (Gregor et al. 1996). Such a scenario would show $\mathrm{Ca}^{2+}$ uptake during the day, due to binding to EPS, and release in the night, as EPS groups become unfavorable to binding. Under such a case of binding and release, the $\mathrm{Ca}^{2+}$ is not precipitated but merely removed from and returned to the water phase. Since EPS can have only a limited number of binding sites, the uptake and release would be transient, occurring during the $\mathrm{pH}$ transitions upon illumination or darkening. No such behavior in $\mathrm{Ca}^{2+}$ microprofiles was observed: typical light and dark profiles were stable for $12 \mathrm{~h}$. The $\mathrm{Ca}^{2+}$ taken up during the day was also clearly precipitated as $\mathrm{CaCO}_{3}$.

Thus, the second scenario is the most probable: biofilm photosynthetic activity changes conditions at the stromatolite-water interface (the site of precipitation), by removal of $\mathrm{CO}_{2}$, to such an extent that rapid $\mathrm{CaCO}_{3}$ precipitation occurs.

As reported in Arp et al. (2001), the stromatolite biofilms were dominated by cyanobacteria and diatoms. The pigment data show that the community is stable when removed from the creek to the laboratory, and it is thus an

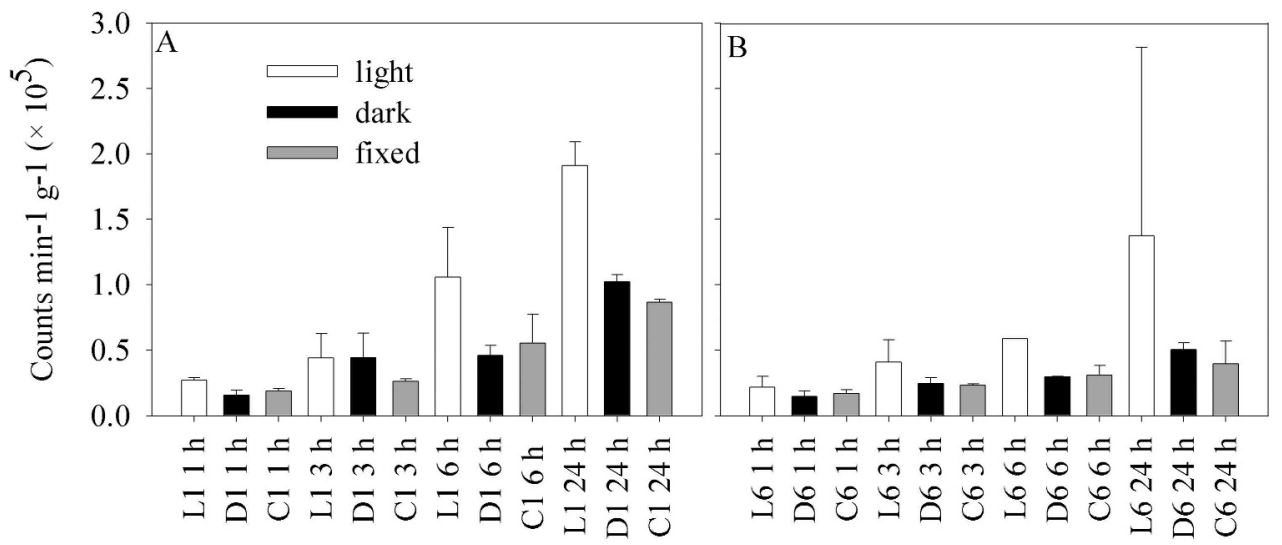

Fig. 7. ${ }^{45} \mathrm{Ca}^{2+}$ uptake of tufa samples from Deinschwanger creek: (A) site 1, (B) site 2. Open bars represent light incubations, black bars dark represent incubations, and gray bars represent formaldehyde fixed controls. $X$-axis labels refer to light (L), dark (D) and control (C) incubations as well as incubations time (h) (mean $\pm \mathrm{SE}, n=2$ ). 

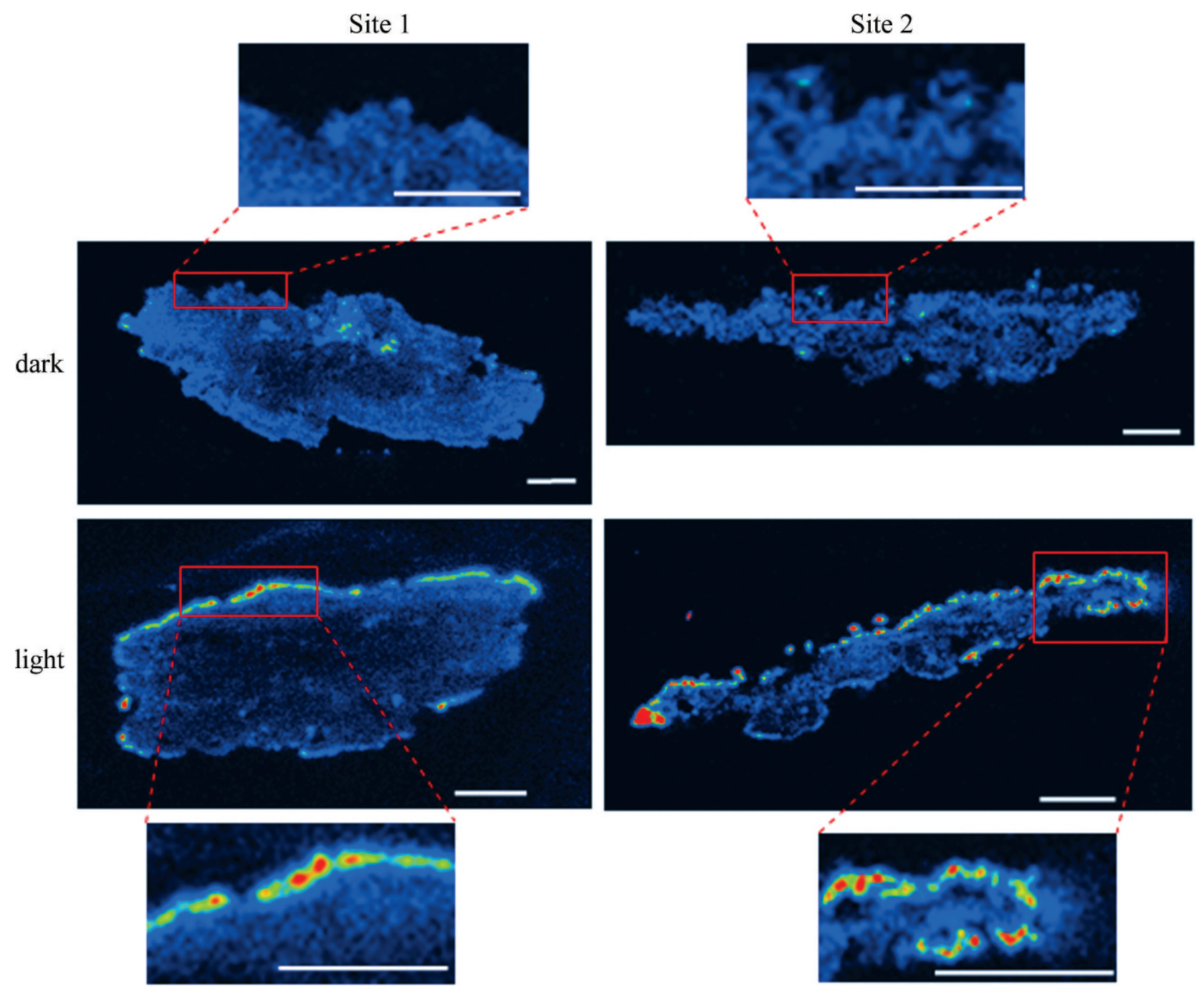

Fig. 8. $\quad \beta$-images of light- and dark-incubated tufa samples from Deinschwanger creek after $24 \mathrm{~h}$. The original biofilm surface is at the top of each sample. Scale bar $=3 \mathrm{~mm}$.

appropriate model for ex situ experimental investigations. Water-chemistry parameters also varied somewhat between our in situ and ex situ measurements. The $\mathrm{Ca}^{2+}$ and DIC concentrations decreased as the incubations continued. Particulate deposits were observed on the base of the recirculating incubation system, but a light-dark pattern to calcium loss was only observed at the stromatolite surface. The loss of $\mathrm{Ca}^{2+}$ and DIC may be seen in the relatively low bulk-water $\Omega$ values observed during the light in our ex situ measurements (Fig. 6). Despite these variations, and although the resultant rates may differ somewhat between the in situ and ex situ measurements, general patterns remained the same. The differences in rates (which seem generally higher for in situ measurements) might be an effect of the different analytical setups (laboratory vs. creek), or they may be due to the natural variation caused by mat patchiness. The level of replication used for the in situ measurements was necessarily small; thus, quantitative extrapolation of the microsensor observations to wholecreek systems must be done with caution. The general agreement among the processes indicated and patterns observed among the different measurements, however, makes it appropriate to discuss, in general terms, the overall processes occurring in the mats, based on both our in situ and ex situ observations.

The apparent, slight, $\mathrm{Ca}^{2+}$ flux to the water phase in the dark period, despite an $\Omega$ value always greater than 1 , may be explained by dissolution that occurred below the stromatolite surface, in the endolithic part of the biofilm, which the microsensors could not reach. Heterotrophic activity probably continues below this zone and creates an environment conducive to stromatolite dissolution. As the stromatolite dissolves in the dark, $\mathrm{Ca}^{2+}$ diffuses upward, past the stromatolite surface, and is recorded by microsensors as $\mathrm{Ca}^{2+}$ flux from the stromatolite.

The importance of photosynthesis, not merely the presence of the biofilm and its potential nucleation sites, was also shown by the incubation of samples with the radioactive tracer ${ }^{45} \mathrm{Ca}^{2+}$. Incorporation rates of the tracer were highest in the photosynthesizing sample, and $\beta$ imaging showed that the tracer was specifically incorporated in the biofilm-covered surfaces. The incorporation 
can be seen at or just below the surface of the lightincubated samples (Fig. 8). The region just below the surface is within the biofilm and would be the zone of highest $\mathrm{pH}$. The incorporation seen occasionally at the base of the samples was not an artifact. The samples were incubated in aquariums for several weeks, and the biofilms had colonized parts of the underneath and sides of the samples. Thus, both the light-stimulated uptake rates and the distribution of tracer incorporation are compatible with photosynthetically driven calcification.

It is interesting that not only was the calcium flux toward the stromatolite surface higher in the in situ measurements, but so was the rate of photosynthesis. This agrees with laboratory results on flow rates, which suggest that photosynthesis should be lower in the slower flow rates of the laboratory.

Because replication in this study was low, the exact rates determined herein need to be taken with some caution, but the diurnal pattern and net precipitation (rather than net dissolution) over the light : dark cycle observed here were remarkably persistent over all samples.

While further studies are needed to elucidate the exact mechanism and rates of nucleation and precipitation in these stromatolite creek systems, the biological activity of their phototrophic communities appears to be much more important than previously thought. Despite not driving the total-stream carbonate-system dynamics, the biofilm has a strong influence over the state of the carbonate system at the sites of nucleation. We have demonstrated this, for the first time, by observing a strong diurnal pattern in $\mathrm{Ca}^{2+}$ and $\mathrm{CO}_{3}^{2-}$ concentration profiles and $\Omega$, a pattern that coincides with the photosynthetic activity of the biofilm.

\section{References}

Arp, G., A. Reimer, And J. Reitner. 2003. Microbialite formation in seawater of increased alkalinity, Satonda Crater Lake, Indonesia. J. Sed. Res. 73: 105-127.

- N. Wedemeyer, and J. Reitner. 2001. Fluvial tufa formation in a hard-water creek (Deinschwanger Bach, Franconian Alb, Germany). Facies 44: 1-22.

Broeker, W. S., And T. H. Peng. 1974. Gas exchange rates between air and sea. Tellus 26: 21-35.

de Beer, D., M. Kühl, N. Stambler, and L. Vaki. 2000. A microsensor study of light enhanced $\mathrm{Ca}^{2+}$ uptake and photosynthesis in the reef-building hermatypic coral Favia sp. Mar. Ecol. Prog. Ser. 194: 175-185.

$\longrightarrow$ A. Schramm, C. M. Santegoeds, and M. Kühl. 1997. A nitrite microsensor for profiling environmental biofilms. Appl. Envir. Microb. 63: 973-977.

Deсно, A. W. 1990. Microbial exopolymer secretions in ocean environments - their role(s) in food webs and marine processes. Oceanogr. Mar. Biol. Ann. Rev. 28: 73-153.

— AND G. R. Lopez. 1993. Exopolymer microenvironments of microbial flora: Multiple and interactive effects on trophic relationships. Limnol. Oceanogr. 38: 1633-1645.

- , P. T. Visscher, And R. P. Reid. 2005. Production and cycling of natural microbial exopolymers (EPS) within a marine stromatolite. Palaeogeogr. Palaeoclim. Palaeoecol. 219: $71-86$.

Dupraz, C., AND P. T. Visscher. 2005. Microbial lithification in marine stromatolites and hypersaline mats. Trends Microbiol. 13: $429-438$.
Epstein, S. S. 1997. Microbial food webs in marine sediments. 1. Trophic interactions and grazing rates in two tidal flat communities. Microb. Ecol. 34: 188-198.

Gieseke, A., And D. DE Beer. 2004. Use of microelectrodes to measure in situ microbial activities in biofilms, sediments, and microbial mats, p. 1581-1612. In G. A. Kowalchuk, F. J. de Bruijn, I. M. Head, A. D. Akkermans and J. D. van Elsas [eds.], Molecular microbial ecology manual, Kluwer.

Gregor, J. E., E. Fenton, G. Brokenshire, P. Van Den Brink, AND B. O'Sullivan. 1996. Interactions of calcium and aluminium ions with alginate. Water Res. 30: 1319-1324.

GRÜNINGER, W. 1965. Rezente Kalktuffbildung im Bereich der Uracher Wasserfälle. Abhand Karst. und Höhlen. Reihe E Bot. 2: $1-113$.

Herman, J. S., and M. M. Lorah. 1987. $\mathrm{CO}_{2}$ outgassing and calcite precipitation in Falling Spring Creek, Virginia, U.S.A. Chem. Geol. 62: 251-262.

Irion, G., AND G. Müller. 1968. Mineralogy, petrology and chemical composition of some calcareous tufa from the Schwäbische Alb, Germany, p. 157-171. In G. Müller and G. M. Friedman [eds.], Recent developments in carbonate sedimentology in central Europe. Springer.

Laniece, P., Y. Charon, A. Cardona, L. Pinot, S. Maitrejean, R. Mastrippolito, B. Sandkamp, and L. Valentin. 1998. A new high resolution radioimager for the quantitative analysis of radiolabelled molecules in tissue section. J. Neurosci. Meth. 86: $1-5$.

Li, Y., AND S. GREGory. 1974. Diffusion of ions in seawater and in deep-sea sediments. Geochim. Cosmochim. Acta 38: 703-714.

Ludwig, R., F. A. Al-Horani, D. De Beer, And H. Jonkers. 2005. Photosynthesis controlled calcification in a hypersaline microbial mat. Limnol. Oceanogr. 50: 1836-1843.

Merz-Preiss, M., and R. Riding. 1999. Cyanobacterial tufa calcification in two freshwater streams: Ambient environment, chemical thresholds and biological processes. Sediment. Geol. 126: 103-124.

Millero, F. J. 1979. The thermodynamics of the carbonate system in seawater. Geochim. Cosmochim. Acta 43: 1651-1661.

Nealson, K. H. 1997. Sediment bacteria: Who's there, what are they doing and what's new? Ann. Rev. Earth Planet. Sci. 25: 403-434.

Neu, T. R., And J. R. Lawrence. 1999. In situ characterization of extracellular polymeric substances (EPS) in biofilm systems, p. 21-47. In J. Wingender, T. R. Neu and H.-C. Flemming [eds.], Microbial extracellular polymeric substances. Springer-Verlag.

Pentecost, A. 1995. Geochemistry of carbon dioxide in six travertine-depositing waters of Italy. J. Hydrol. 167: 263-278.

PiA, J. 1926. Pflanzen als Gesteinsbildner. Borntraeger.

— 1933. Die rezenten Kalksteine. Ergänzungsband.

Plummer, L. N., and E. Busenberg. 1982. The solubilities of calcite, aragonite and vaterite in $\mathrm{CO}_{2}-\mathrm{H}_{2} \mathrm{O}$ solutions between 0 and $90^{\circ} \mathrm{C}$, and an evolution of aqueous model for the system $\mathrm{CaCO}_{3}-\mathrm{CO}_{2}-\mathrm{H}_{2} \mathrm{O}$. Geochim. Cosmochim. Acta 46: 1011-1040.

Revsbech, N. P. 1989. An oxygen microsensor with a guard cathode. Limnol. Oceanogr. 34: 474 478.

Riding, R. 1990. Calcareous algae and stromatolites. SpringerVerlag.

Spiro, B., And A. Pentecost. 1991. One day in the life of a stream-a diurnal inorganic carbon mass balance for a travertine-depositing stream (Waterfall Beck, Yorkshire). Geomicrobiol. Jour. 9: 1-11.

Staats, N., L. J. Stal, B. de Winder, and L. R. Mur. 2000. Oxygenic photosynthesis as driving process in exopolysaccharide production of benthic diatoms. Mar. Ecol. Prog. Ser. 193: $261-269$. 
Trichet, J., And C. Defarge. 1995. Non-biologically supported organomineralization. Bull. Inst. Océanogr. 14: 203-236.

Usdowski, E., J. Hoefs, and G. Menschel. 1979. Relationship between ${ }^{13} \mathrm{C}$ and ${ }^{18} \mathrm{O}$ fractionation and changes in major element composition in a recent calcite-depositing spring - a model of chemical variations with inorganic $\mathrm{CaCO}_{3}$ precipitation. Earth Planet. Sci. Lett. 42: 267-276.

WAllner, J. 1934. Über die Beteiligung kalkablagernder Pflanzen bei der Bildung südbayerischer Tuffe. Bibliotheca Bot. 110: 1-30.

Werner, U., A. Blazejak, P. Bird, G. Eickert, R. Schoon, R. M. M. Abed, A. Bissett, and D. De Beer. 2008. Microbial photosynthesis in coral reef sediments (Heron Reef, Australia). Estuar. Coast. Shelf Sci. 76: 876-888.
Wright, S. W., S. W. Jeffrey, R. F. C. Mantoura, C. A Llewellyn, T. Buornland, D. Repeta, and N. WelschMEYER. 1991. Improved HPLC method for the analysis of chlorophylls and carotenoids from marine-phytoplankton. Mar. Ecol. Prog. Ser. 77: 183-196.

Zeebe, R. E., and D. Wolf-Gladrow. 2001. $\mathrm{CO}_{2}$ in seawater: Equilibrium, kinetics, isotopes, 1st ed. Elsevier.

Received: 17 July 2007 Accepted: 6 December 2007 Amended: 7 January 2008 